\title{
Dampak pembangunan Jalan Balige bypass terhadap alih fungsi lahan Kabupaten Toba
}

\author{
(Effects of the Balige bypass road construction on the land conversion in Toba Regency) \\ Dian Pranata Tampubolon*, Westi Utami**1, Sutaryono** \\ * Kantor Pertanahan Kabupaten Toba, Jl. Somba Debata No.3, Balige III, Balige, Toba, Sumatera \\ Utara, 22312, Indonesia \\ ** Sekolah Tinggi Pertanahan Nasional, Jl. Tata Bumi, No. 5, Gamping, Sleman, Yogyakarta, 55293, \\ Indonesia \\ ${ }^{1}$ Corresponding author, Surel: westiutami@stpn.ac.id
}

Paper received: 27-09-2021; revised: 01-11-2021; accepted: 16-12-2021

\begin{abstract}
Infrastructure development often has an impact on land use changes. This study aims to map the impact of Balige bypass road construction on land use changes and analyze its suitability with spatial planning. The research method was carried out through descriptive qualitative with a spatial approach. The data includes Sentinel images for 2017 and 2021, maps of the Regional Spatial Plan (RTRW) and interviews with government officials. Image analysis is carried out visually, while mapping of land use changes is carried out through overlaying land use maps for 2017 and 2021 and to map the suitability of the RTRW, overlaying land use maps with the RTRW. The results of the analysis show that after the road construction there was a change in land use from rice fields to settlements covering an area of $103.27 \mathrm{Ha}$. Meanwhile, an analysis of the RTRW shows that there is a mismatch in the use of a land area of $47.2 \mathrm{Ha}$. This study shows that the use of remote sensing through sentinel imagery and spatial analysis can be a tool for monitoring natural resources, this study is also useful as material for developing Geography learning.
\end{abstract}

Keywords: land acquisition; land use; infrastructure development

\begin{abstract}
Abstrak
Pembangunan infrastruktur seringkali berdampak pada perubahan penggunaan tanah. Penelitian ini bertujuan memetakan dampak pembangunan jalan Balige bypass terhadap perubahan penggunaan tanah dan menganalisis kesesuaiannya dengan tata ruang. Metode penelitian dilakukan melalui kualitatif deskriptif dengan pendekatan spasial. Data yang digunakan meliputi citra Sentinel tahun 2017 dan 2021, peta Rencana Tata Ruang Wilayah (RTRW) serta wawancara dengan pejabat pemerintahan. Analisis citra dilakukan secara visual, sementara pemetaan perubahan penggunaan tanah dilakukan melalui overlay peta penggunaan tanah 2017 dengan 2021, dan untuk memetakan kesesuaian RTRW dilakukan overlay peta penggunaan tanah dengan RTRW. Hasil analisis menunjukkan pasca pembangunan jalan terjadi perubahan penggunaan tanah dari sawah menjadi pemukiman seluas 103,27 Ha. Sementara analisis terhadap RTRW menunjukkan terjadi ketidaksesuaian penggunaan lahan seluas 47,2 Ha. Kajian ini menunjukkan pemanfaatan penginderaan jauh melalui citra sentinel serta analisis spasial mampu menjadi alat monitoring sumber daya alam, kajian ini juga bermanfaat sebagai bahan pengembangan pembelajaran ilmu Geografi.
\end{abstract}

Kata kunci: pengadaan tanah; penggunaan tanah; pembangunan infrastruktur 


\section{Pendahuluan}

Pembangunan infrastruktur maupun pertumbuhan penduduk pada suatu wilayah mengakibatkan kebutuhan atas lahan semakin meningkat (Ghatak \& Mookherjee, 2014; Putri, 2020; Tantja et al., 2021). Hal inilah yang memicu terjadinya tekanan pemanfaatan ruang maupun penggunaan lahan terutama pada wilayah dengan lokasi strategis/memiliki nilai ekonomi tinggi (Muhajir, 2017). Tekanan terhadap ruang/tanah yang terus meningkat membawa dampak pada semakin meningkatnya permasalahan/konflik pemanfaatan atas ruang (Katiandagho et al., 2017; Utami, Wibowo, et al., 2021; Zhang et al., 2021). Hasil kajian beberapa peneliti menunjukkan pembangunan infrastruktur maupun kebutuhan masyarakat akan pemukiman seringkali harus mengorbankan lahan sawah yang berujung pada penurunan luas lahan pertanian (Tantja et al., 2021; Utami, Nurcahyanto, et al., 2021). Perubahan penggunaan tanah dari pertanian menjadi non pertanian yang terus terjadi tentu akan memberikan ancaman ketahanan pangan maupun krisis pangan (Janti et al., 2016; Kaputra, 2015). Ancaman ini selanjutnya melahirkan berbagai strategi untuk mengupayakan keberlanjutan keamanan pangan sebagai program prioritas di beberapa negara (Muryono \& Utami, 2020; Rudel \& Meyfroidt, 2014). Cina salah satunya sebagai negara penghasil seperempat pangan dunia menempatkan agenda ketahanan pangan dalam sistem politik dan menjadikan upaya perlindungan lahan pertanian/pangan sebagai prioritas utama dalam setiap pengambilan kebijakan (Zhou \& Liu, 2021). Regulasi yang ditetapkan di beberapa negara ini dilakukan untuk menekan dampak buruk tekanan terhadap ruang/masyarakat di pedesaan (Buchori et al., 2020; Festus et al., 2020).

Perpindahan penduduk dari pedesaan ke perkotaan (urbanisasi), agenda pembangunan maupun pertumbuhan wilayah perkotaan yang semakin pesat juga berimplikasi terhadap munculnya 'Urban Sprawl' (Festus et al., 2020). Fenomena pertumbuhan/pemekaran kota yang tidak terencana/tidak terstruktur yang terjadi pada beberapa wilayah ini membawa dampak buruk terhadap perubahan lahan di daerah pinggiran kota sebagai kawasan penyangga maupun sebagai kawasan lahan pertanian (Latifah, 2014). Dalam konteks ini semakin menegaskan pertumbuhan penduduk, urbanisasi maupun pembangunan seringkali mengakibatkan pergesekan antar kepentingan terkait pemanfaatan ruang, terjadinya penyimpangan penggunaan tanah serta degradasi lingkungan (Khaerani et al., 2018; Kusiluka et al., 2011).

Pembangunan infrastruktur guna menopang pertumbuhan perekonomian serta pemerataan pembangunan menjadi salah satu program prioritas pemerintah. Di satu sisi agenda ini memberikan kebermanfaatan diantaranya terpenuhinya infrastrutur yang memadai sehingga mendorong peningkatan perekonomian, namun di sisi lain dampak negatifnya mendorong alih fungsi lahan dan perubahan struktur ruang (Yin et al., 2020). Program pembangunan infrastrutur ini terus digalakkan salah satunya dilakukan di Kabupaten Toba, Sumatera Utara. Infrastruktur yang dibangun berupa jalan Balige bypass di Kecamatan Balige dilakukan dalam kurun waktu empat tahun (2017-2021). Tujuan pembangunan ini diantaranya untuk mengurai kemacetan di pusat kota Balige, mengurangi kesemrawutan serta menciptakan ruang yang kondusif (Tinambunan et al., 2020). Pembangunan infrastruktur selain memberikan dampak positif juga memberikan dampak negatif (Karmakar, 2017), diantaranya terjadinya peningkatan alih fungsi lahan pertanian yang berdampak terhadap menurunnya pendapatan petani serta ancaman ketahanan pangan (Sopanudin, 2016; Yin et al., 2020). Selain itu alih fungsi yang terjadi tanpa adanya kontrol yang optimal dapat berpengaruh terhadap timbulnya ketidaksesuaian pemanfaatan ruang. Dalam konteks ini maka pengaturan, 
Jurnal Pendidikan Geografi:

Kajian, Teori, dan Praktek dalam Bidang Pendidikan dan Ilmu Geografi

27(1), 2022, 1-14

perlindungan dan pengendalian terhadap pemanfaatan ruang yang dituangkan dalam Rencana Tata Ruang Wilayah (RTRW) guna mewujudkan pembangunan berkelanjutan menjadi hal penting untuk diimplementasikan.

Kebijakan dan pengaturan terhadap pemanfaatan dan penggunaan ruang ini harapannya mampu mendorong terwujudnya Sustainable Development Goals (SDGs) (Verma \& Raghubanshi, 2019), terutama bagi Indonesia sebagai salah satu negara penghasil pangan. Upaya perlindungan dan pengaturan terhadap pemanfaatan fungsi ruang tentu menjadi pengendali utama agar ruang/lahan yang tersedia memberikan porsi yang seimbang dan adil terhadap peningkatan pertumbuhan perekonomian, keadilan, perlindungan kawasan setempat/ruang yang berfungsi sebagai konservasi maupun ruang/lahan yang berfungsi sebagai sumber keberlanjutan ketahanan pangan (Nixon \& Newman, 2016). Dalam konteks ini maka peran pemerintah menjadi unsur perencana, penyelenggara, penegakan hukum maupun pengendali terhadap fungsi ruang sangatlah penting, sementara masyarakat sebagai pengguna/penerima manfaat terhadap ruang tentu harus memiliki kesadaran, kepatuhan dan ketaatan terhadap rencana tata ruang yang telah ditetapkan. Kolaborasi antara pemerintah, masyarakat, korporasi maupun pemerhati lingkungan menjadi salah satu unsur penting agar ruang yang sifatnya terbatas mampu memberikan kebermanfaatan bagi kesejahteraan masyarakat serta keberlanjutan lingkungan (Jazuli, 2017). Berdasarkan dari beberapa problematika yang telah diuraikan di atas, kajian ini bertujuan untuk melakukan pemetaan terhadap perubahan penggunaan tanah pasca dilakukannya pembangunan jalan Balige bypass, memetakan tingkat ketidaksesuaian yang terjadi pasca pembangunan jalan Balige bypass, dan mengetahui kebijakan yang direncanakan pemerintah pasca pembangunan jalan Balige bypass.

\section{Metode}

Penelitian ini menggunakan metode kualitatif deskriptif dengan pendekatan spasial. Metode kualitatif desktiptif ini dipilih dengan harapan mampu mendeskripsikan keadaan yang ada di lapangan melalui pengamatan, sehingga hasil yang diharapkan lebih spesifik dan mendalam (Sugiono, 2007). Sementara pendekatan spasial merupakan suatu metode yang digunakan dengan menekankan analisisnya terhadap eksistensi ruang sebagai satu kesatuan wadah yang difungsikan untuk mengakomodasi kegiatan manusia dalam menjelaskan fenomena geosfer (Yunus, 2008).

Data yang digunakan dalam penelitian ini meliputi: 1) citra satelit Sentinel-2 liputan bulan Maret 2017 dan bulan April 2021 yang diperoleh melalui website Sentinel Hub (sentinelhub.com) dengan resolusi spasial $10 \mathrm{~m}$; 2) data koordinat hasil ground check; 3) peta Rencana Tata Ruang Wilayah Kabupaten Toba Tahun 2017-2037 skala 1: 100.000 yang diperoleh dari Pemerintah Kabupaten Toba dalam bentuk data shp; 4) data wawancara dengan Sekretaris Dinas PUPR Kabupaten Toba (Gumianto Simangunsong, M.M.); dan dengan Kepala Seksi Penataan dan Pemberdayaan Kantor Pertanahan Kabupaten Toba (Peresli Silitonga, M.M.). Untuk memetakan pengunaan lahan maka dilakukan interpretasi citra sentinel dengan menggunakan teknik secara visual (menggunakan 9 kunci interpretasi). Sementara untuk kriteria klasifikasi penggunaan tanah mengacu dalam pedoman Norma, Standar, Prosedur, Kriteria (NSPK) Pemetaan Tematik Pertanahan Tahun 2012 untuk skala 1: 50.000. Hasil klasifikasi penggunaan lahan dibagi menjadi 10 kelas yakni: hutan lebat, hutan sejenis, kampung, perkebunan, perumahan, sawah irigasi, sawah non irigasi, sungai, taman dan tempat bersejarah. 
Jurnal Pendidikan Geografi:

Kajian, Teori, dan Praktek dalam Bidang Pendidikan dan Ilmu Geografi

$27(1), 2022,1-14$

Tabel 1. Matriks Kesalahan

\begin{tabular}{|c|c|c|c|c|c|c|}
\hline & & $\begin{array}{l}\text { Hasil } \\
\text { Interpretasi } \\
\text { Perumahan }\end{array}$ & Jumlah & $\begin{array}{l}\text { Procedur's } \\
\text { Accuracy }\end{array}$ & $\begin{array}{l}\text { PA } \\
(\%)\end{array}$ & $\begin{array}{l}\text { Omisi } \\
\text { Kesalahan } \\
(\%)\end{array}$ \\
\hline Data & Perumahan & 26 & 26 & 1,00 & 100 & 0 \\
\hline \multirow[t]{2}{*}{ Acuan } & Sawah Irigasi & 1 & 1 & 0,00 & 0 & 0 \\
\hline & $\begin{array}{l}\text { Sawah Non } \\
\text { Irigasi }\end{array}$ & 3 & 3 & 0,00 & 0 & 0 \\
\hline \multicolumn{2}{|l|}{ Jumlah } & 30 & 30 & 1 & 100 & 0 \\
\hline \multicolumn{2}{|c|}{ User Accuracy } & 0,87 & 0,87 & & & \\
\hline \multicolumn{2}{|c|}{ UA (\%) } & 86,67 & 86,67 & & & \\
\hline \multicolumn{2}{|c|}{ Komisi Kesalahan (\%) } & 13,33 & 13,33 & & & \\
\hline
\end{tabular}

Hasil interpretasi citra secara visual pada citra satelit Sentinel-2 menghasilkan peta penggunaan tanah tahun 2017 dan tahun 2021. Sebagai upaya untuk melakukan uji ketelitian penggunaan tanah tahun 2021, peneliti melakukan ground check lapang. Akurasi sampel penguji dalam penelitian berupa titik dan dihitung menggunakan matriks kesalahan atau confusion matrix/error matrix yang selanjutnya dapat dilakukan perhitungan producer's accuracy, user's accuracy, overall accuracy dan indeks kappa. Semakin besar nilai yang diperoleh maka akan semakin akurat (Chulafak et al., 2018). Jumlah titik ground check dalam penelitian ini adalah 30 titik yang tersebar di sepanjang jalan Balige bypass. Selanjutnya data sampel ground check diolah menggunakan matriks kesalahan yang disajikan pada Tabel 1.

Hasil matriks kesalahan pada Tabel 1 menunjukkan overall accuracy sebesar 86,67 \%. Nilai ini sudah memenuhi standar perolehan data penggunaan tanah eksisting. Beberapa kesalahan yang terjadi dalam proses klasifikasi yakni terhadap obyek pengunaan lahan berupa perumahan.

Peneliti melakukan overlay peta penggunaan tanah tahun 2017 dengan tahun 2021 sebagai upaya memetakan dampak pembangunan Jalan Balige bypass terhadap alih fungsi lahan. Selanjutnya terhadap data perubahan penggunaan tanah tersebut dilakukan overlay dengan peta RTRW untuk mengetahui tingkat ketidaksesuaian lahan yang terjadi akibat adanya pembangunan jalan Balige bypass. Mekanisme dalam melakukan analisis kesesuaian antar instrumen tersebut dilakukan melalui beberapa tahap sebagai berikut:

\subsection{Menyusun Matriks Kriteria Kesesuaian, Belum Sesuai dan Ketidaksesuaian}

Dalam melakukan penyusunan matrik kesesuaian dan ketidaksesuaian terdapat beberapa kriteria meliputi: a) Sesuai (S), dikatakan sesuai apabila penggunaan tanah sudah sesuai dengan arahan pola ruang dalam RTRW. Misalnya, pada peta penggunaan tanah terdapat penggunaan tanah untuk perkampungan, maka dalam peta RTRW merupakan pola ruang untuk pemukiman. b) Belum Sesuai (BS), dikatakan belum sesuai apabila penggunaan tanah belum berubah menjadi peruntukan dalam RTRW. Misalnya, pada peta penggunaan tanah eksisting terdapat penggunaan tanah untuk tanah pertanian, sementara dalam peta RTRW arahan pola ruangnya perkampungan. c) Tidak Sesuai (TS), dikatakan tidak sesuai apabila penggunaan tanah tidak sesuai dengan arahan pola ruang dalam RTRW. Sebagai contoh, terdapat penggunaan tanah eksisting untuk perkampungan, namun pada peta RTRW pola ruangnya adalah perkebunan. 
Jurnal Pendidikan Geografi:

Kajian, Teori, dan Praktek dalam Bidang Pendidikan dan Ilmu Geografi

$27(1), 2022,1-14$

Tabel 2. Matriks Penggunaan Tanah Terhadap RTRW

\begin{tabular}{lllll}
\hline & \multicolumn{4}{c}{ Peta PT } \\
\cline { 2 - 5 } Peta RTRW & Hutan & Perkampungan & Pertanian & Sungai \\
\hline Hutan Lindung & S & TS & TS & TS \\
Hutan Produksi Tetap & S & TS & TS & TS \\
Perkebunan & TS & TS & S & TS \\
Permukiman & TS & S & BS & TS \\
Pertanian Lahan Basah & TS & TS & S & TS \\
Pertanian Lahan Kering & TS & TS & S & TS \\
Sungai & TS & TS & TS & S \\
\hline
\end{tabular}

Berdasarkan hasil analisis tingkat kesesuaian penggunaan lahan maka identifikasi kriteria kesesuaian pada masing-masing penggunaan tanah dalam arahan pola ruang RTRW dapat disajikan pada Tabel 2. Adanya ketidaksesuaian penggunaan lahan ini selanjutnya menjadi dasar untuk melakukan diskusi/wawancara dengan stakeholder terkait, yakni Dinas PUPR Kabupaten Toba serta Seksi Penataan dan Pemberdayaan Kantor Pertanahan Kabupaten Toba guna mengetahui arahan kebijakan yang direncanakan oleh pemerintah.

\section{Hasil dan Pembahasan}

Pembangunan jalan Balige bypass mulai dilaksanakan di tahun 2017, dimana pembangunan ini salah satunya bertujuan untuk menekan tingkat kemacetan pada poros jalan utama Kabupaten Toba. Pembangunan jalan Balige bypass sepanjang 9,8 Km ini sebagian besar membelah lahan pertanian masyarakat. Di dalam proses perencanaan pengadaan tanah, pemilihan lokasi melalui studi kelayakan guna pembangunan jalan Balige bypass diputuskan untuk diupayakan tidak berada pada pemukiman padat penduduk. Sehingga pemilihan lokasi pembangunan sebagian besar mengenai lahan pertanian agar nilai kompensasi yang diberikan biayanya lebih rendah. Selain itu pembangunan yang tidak dilakukan di komplek pemukiman lebih memudahkan instansi yang membutuhkan tanah karena tidak perlu melakukan pemindahan/relokasi penduduk. Peneliti melakukan interpretasi citra sentinel dengan kemampuan resolusi spasial $10 \mathrm{~m}$ untuk memetakan penggunaan tanah sebelum pembangunan jalan Balige bypass. Adapun hasil interpretasi citra berupa peta penggunaan tanah tahun 2017 disajikan pada Gambar 1.

Berdasarkan Gambar 1 menunjukkan bahwasanya pembangunan jalan mengenai lahan sawah irigasi yang telah dibudidayakan oleh masyarakat, dan hanya sebagian kecil melewati kawasan perkampungan maupun perumahan warga. Adapun kondisi luasan penggunaan tanah sebelum dibangunnya jalan Balige bypass dapat disajikan pada Tabel 3.

Berdasarkan Tabel 3, penggunaan tanah di Kecamatan Balige pada tahun 2017 didominasi oleh penggunaan tanah sawah yaitu seluas 3.987,55 ha dengan persentase $51,69 \%$ yang terdiri dari sawah irigasi dengan luas $2.005,71$ ha $(26 \%)$ dan sawah non irigasi dengan luas $1.981,84$ ha $(25,69 \%)$. Sedangkan penggunaan tanah perumahan memiliki luas 1.108,06 ha dengan persentase 14,36\%. Kondisi penggunaan lahan pada wilayah sekitar jalan Balige bypass didominasi oleh sawah dan hanya sebagian kecil berupa pemukiman. Penggunaan tanah di tahun 2017 sebelum pengadaan tanah dapat dikatakan sebagian besar berupa lahan sawah beririgasi teknis, Effendi dan Asmara (2014) menyatakan bahwasanya pembangunan infrastruktur khususnya jalan yang dibangun melintasi sawah irigasi teknis dapat mengancam keberadaan sawah dan semakin mempercepat terjadinya alih fungsi lahan. 


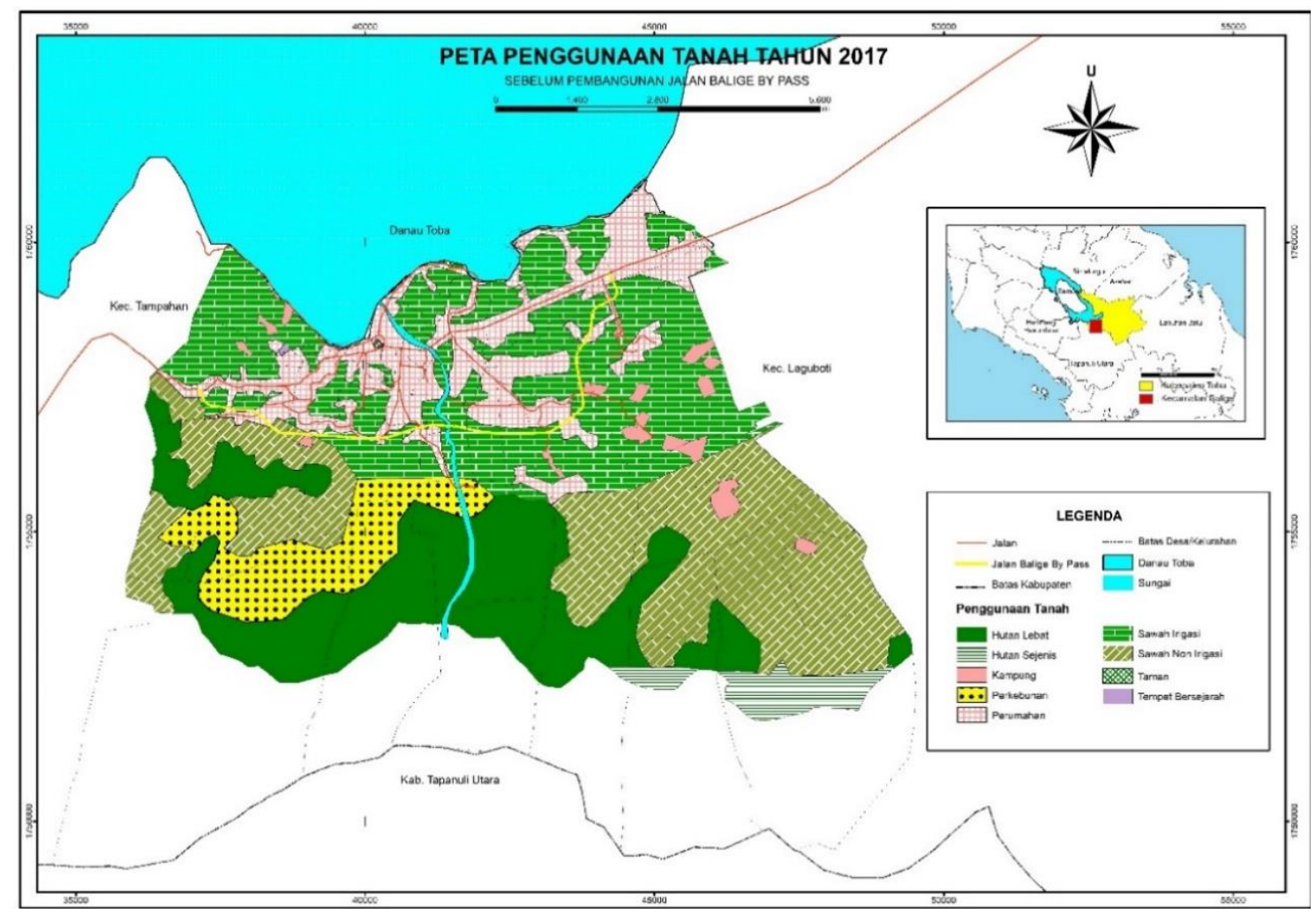

Gambar 1. Peta Penggunaan Tanah Tahun 2017 Sumber: Interpretasi Citra Sentinel-2 liputan bulan Maret 2017

\section{Tabel 3. Penggunaan Tanah Tahun 2017 di Kecamatan Balige}

\begin{tabular}{llll}
\hline No & Jenis Penggunaan Tanah & Luas (Ha) & Persentase (\%) \\
\hline 1 & Sawah Irigasi & $2.005,71$ & 26 \\
2 & Sawah Non Irigasi & $1.981,84$ & 25,69 \\
3 & Hutan Lebat & $1.670,60$ & 21,66 \\
4 & Perumahan & $1.108,06$ & 14,36 \\
5 & Perkebunan & 572,36 & 7,42 \\
6 & Hutan Sejenis & 216,91 & 2,81 \\
7 & Kampung & 132,84 & 1,72 \\
8 & Sungai & 21,91 & 0,28 \\
9 & Tempat Bersejarah & 2,05 & 0,03 \\
10 & Taman & 1,36 & 0,02 \\
\hline & Jumlah & $7.713,64$ & 100 \\
\hline
\end{tabular}

\subsection{Penggunaan Tanah Tahun 2021}

Pembangunan jalan Balige bypass yang hampir terselesaikan di pertengahan tahun 2021, membawa perubahan yang cukup signifikan terhadap penggunaan tanah di sekitar jaringan jalan. Berdasarkan hasil interpretasi citra sentinel maka sebaran penggunaan lahan pasca dibangunnya jalan Balige bypass di tahun 2021 disajikan pada Gambar 2.

Berdasarkan Gambar 2 menunjukkan bahwasanya pasca pembangunan jalan, alih fungsi lahan cukup massif terjadi. Salah satu perubahan yang cukup signifikan yakni terjadinya perubahan dari lahan pertanian menjadi pemukiman. Dengan dibangunnya akses jalan ini 
Jurnal Pendidikan Geografi:

Kajian, Teori, dan Praktek dalam Bidang Pendidikan dan Ilmu Geografi

$27(1), 2022,1-14$

tentu menjadikan lahan yang terdapat pada kanan-kiri jalan sangat strategis jika dibangun sebagai pemukiman. Adanya akses jalan memudahkan masyarakat untuk bermukim maupun membuka usaha guna meningkatkan perekonomian. Berdasarkan hasil analisis spasial maka jenis penggunaan tanah pasca dibangunnya jalan Balige bypass di tahun 2021 disajikan pada Tabel 4.

Berdasarkan Tabel 4 menunjukkan telah terjadi penurunan luasan lahan sawah di sepanjang pembangunan jalan maupun di sekitar jalan Balige bypass. Pembangunan jalan telah menurunkan luasan lahan sawah hingga mencapai 103,28 Ha atau 1,33\% hanya dalam jangka waktu empat tahun. Alih fungsi ini tentu semakin mempersempit lahan garapan masyarakat yang sebagian menggantungkan hidup pada sektor pertanian.

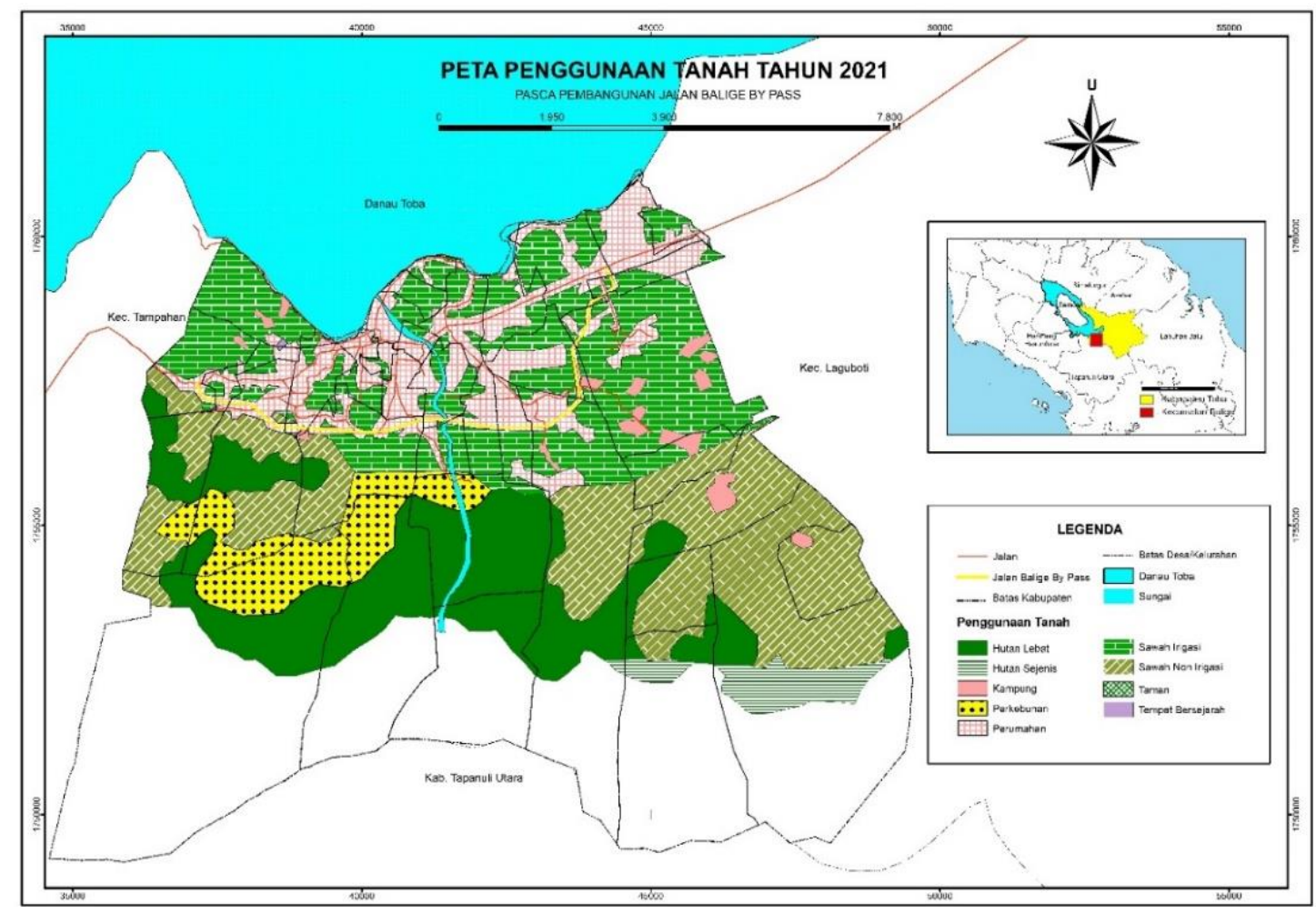

Gambar 2. Peta Penggunaan Tanah Tahun 2021 Sumber: Interpretasi Citra Satelit Sentinel-2 liputan April 2021

Tabel 4. Penggunaan Tanah Tahun 2021 di Kecamatan Balige

\begin{tabular}{llll}
\hline No & Jenis Penggunaan Tanah & Luas (Ha) & Persentase (\%) \\
\hline 1 & Sawah Non Irigasi & $1.969,90$ & 25,54 \\
2 & Sawah Irigasi & $1.914,37$ & 24,82 \\
3 & Hutan Lebat & $1.670,60$ & 21,66 \\
4 & Perumahan & $1.211,33$ & 15,7 \\
5 & Perkebunan & 572,36 & 7,42 \\
6 & Hutan Sejenis & 216,91 & 2,81 \\
7 & Kampung & 132,84 & 1,72 \\
8 & Sungai & 21,91 & 0,28 \\
9 & Tempat Bersejarah & 2,05 & 0,03 \\
10 & Taman & 1,36 & 0,02 \\
\hline & Jumlah & $7.713,64$ & 100 \\
\hline
\end{tabular}


Jurnal Pendidikan Geografi:

Kajian, Teori, dan Praktek dalam Bidang Pendidikan dan Ilmu Geografi

$27(1), 2022,1-14$

\subsection{Perubahan Penggunaan Tanah Tahun 2017-2021}

Pembangunan infrastruktur di berbagai wilayah secara signifikan berkorelasi terhadap laju perubahan penggunaan lahan. Di satu sisi dengan adanya pembangunan ini dapat meningkatkan perekonomian masyarakat, akan tetapi yang perlu menjadi pertimbangan adalah bagaimana dengan keberlanjutan lahan pertanian dan ketahanan pangan suatu wilayah. Dalam kajian ini untuk mengetahui sebaran perubahan penggunaan tanah maka dilakukan overlay peta penggunaan tanah tahun 2021 dengan peta penggunaan tanah tahun 2017. Peta perubahan penggunaan tanah tahun 2017-2021 dapat dilihat pada Gambar 3.

Berdasarkan Gambar 3 menunjukkan bahwa penggunaan lahan yang mengalami perubahan signifikan yakni lahan sawah baik berupa sawah irigasi maupun non irigasi telah berubah fungsi menjadi kawasan pemukiman. Data luasan masing-masing penggunaan tanah yang mengalami pengurangan maupun penambahan akibat pembangunan jalan Balige bypass periode 2017-2021 disajikan pada Tabel 5.

Berdasarkan Tabel 5, jenis penggunaan tanah perumahan mengalami peningkatan luas sebesar 103,27 ha. Sedangkan penggunaan tanah untuk sawah irigasi mengalami penurunan luas sebesar 91,34 ha. Selain itu penurunan luas juga terjadi pada penggunaan tanah untuk sawah non irigasi sebesar 11,93 ha. Data perubahan penggunaan lahan pasca pembangunan disajikan pada Tabel 6.

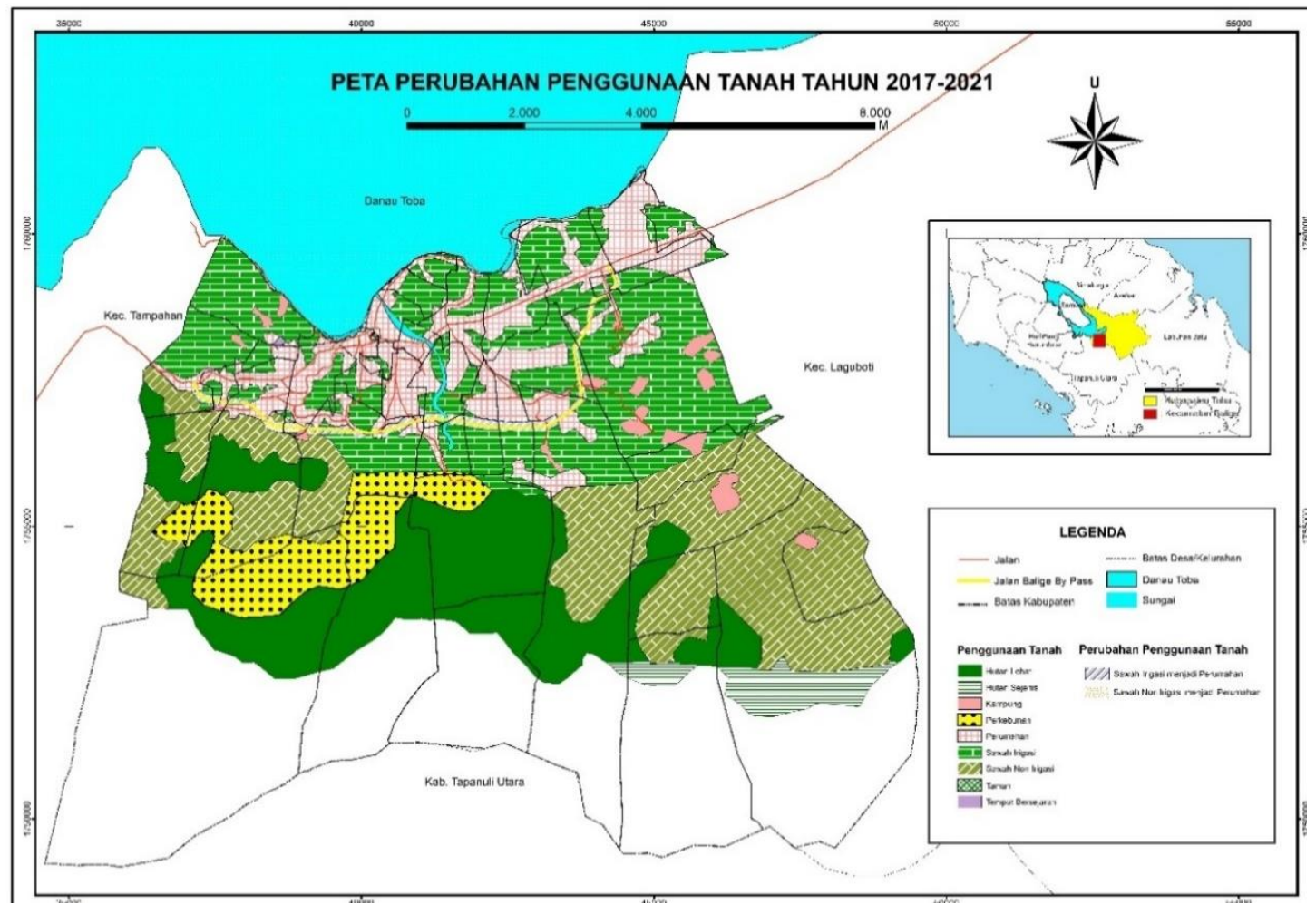

Gambar 3. Peta Perubahan Penggunaan Tanah Tahun 2017-2021 
Jurnal Pendidikan Geografi:

Kajian, Teori, dan Praktek dalam Bidang Pendidikan dan Ilmu Geografi

$27(1), 2022,1-14$

Tabel 5. Perubahan Luas Penggunaan Tanah Periode 2017-2021

\begin{tabular}{lllll}
\hline No & Penggunaan Tanah & Th 2017(Ha) & Th 2021(Ha) & Perubahan (Ha) \\
\hline 1 & Sawah Irigasi & $2.005,71$ & $1.914,37$ & $-91,34$ \\
2 & Sawah Non Irigasi & $1.981,84$ & $1.969,90$ & $-11,93$ \\
3 & Hutan Lebat & $1.670,60$ & $1.670,60$ & 0 \\
4 & Perumahan & $1.108,06$ & $1.211,33$ & $+103,27$ \\
5 & Perkebunan & 572,36 & 572,36 & 0 \\
6 & Hutan Sejenis & 216,91 & 216,91 & 0 \\
7 & Kampung & 132,84 & 132,84 & 0 \\
8 & Sungai & 21,91 & 21,91 & 0 \\
9 & Tempat Bersejarah & 2,05 & 2,05 & 0 \\
10 & Taman & 1,36 & 1,36 & 0 \\
\hline
\end{tabular}

Tabel 6. Perubahan Penggunaan Tanah Periode 2017-2021

\begin{tabular}{lllll}
\hline No & Perubahan & Berubah & Tidak Berubah & Luas \\
\hline 1 & Sawah Non Irigasi - Swh Non Irigasi & $\sqrt{ }$ & $1.969,91$ \\
2 & Sawah Irigasi - Sawah Irigasi & $\sqrt{ }$ & $1.914,37$ \\
3 & Hutan Lebat - Hutan Lebat & $\sqrt{ }$ & $1.670,60$ \\
5 & Perumahan - Perumahan & $\sqrt{ }$ & $1.108,06$ \\
6 & Perkebunan - Perkebunan & $\sqrt{ }$ & 572,36 \\
7 & Hutan Sejenis - Hutan Sejenis & $\sqrt{ }$ & 216,91 \\
8 & Kampung - Kampung & $\sqrt{ }$ & 132,84 \\
9 & Sawah Irigasi - Perumahan & & 91,34 \\
10 & Sungai - Sungai & $\sqrt{ }$ & 21,91 \\
11 & Sawah Non Irigasi - Perumahan & $\sqrt{ }$ & 11,93 \\
12 & Tempat Bersejarah - Tmpt Bersejarah & & $\sqrt{ }$ & 2,05 \\
13 & Taman - Taman & $\sqrt{ }$ \\
\hline
\end{tabular}

Berdasarkan Tabel 6, terdapat 2 jenis penggunaan tanah yang mengalami perubahan penggunaan tanah yaitu penggunaan tanah perumahan, sawah irigasi dan sawah non irigasi. Penggunaan tanah perumahan yang semula memiliki luas 1.108,06 ha mengalami peningkatan luas seluas 103,27 ha, sehingga saat kajian dilakukan mencapai luasan 1.211,33 ha. Pembangunan perumahan yang terus meningkat tersebut berimplikasi terhadap menurunnya lahan sawah irigasi seluas 91,34 ha sehingga total luasan menjadi 1.914,37 ha dan penggunaan tanah sawah non irigasi mengalami penurunan luas sebesar 11,93 ha sehingga luasannya menjadi 1.969,91 ha. Perubahan penggunaan lahan sawah yang terus mengalami peningkatan ini tentu dapat berdampak buruk terhadap keberlanjutan hidup petani maupun produktivitas pangan. Dampak massif alih fungsi lahan ini juga terjadi pasca pengadaan tanah dan pembangunan bandara Yogyakarta Internasional (Utami, Nurcahyanto, et al., 2021) maupun pembangunan infratruktur lain (Tantja et al., 2021). Kondisi ini menunjukkan bahwa petani dan kaum marginal menjadi pihak paling rentan dalam pembangunan (Kustiningsih, 2017). Dalam hal ini maka pengaturan serta pengendalian alih fungsi lahan pertanian memiliki peran penting dalam menekan laju perubahan penggunaan lahan di Kabupaten Toba.

\subsection{Kesesuaian Penggunaan Tanah Pasca Pembangunan terhadap Rencana Tata Ruang Wilayah}

Dalam kajian ini analisis peta ketidaksesuaian dengan pola ruang dilakukan secara bertahap agar dapat diketahui dampak perubahan penggunaan lahan terhadap 
Jurnal Pendidikan Geografi:

Kajian, Teori, dan Praktek dalam Bidang Pendidikan dan Ilmu Geografi

$27(1), 2022,1-14$

ketidaksesuaian tata ruang. Pada peta kesesuaian penggunaan tanah tahun 2017 (Gambar 4) dianalisis bahwa penggunaan tanah yang sesuai dengan peruntukan dalam RTRW adalah seluas $7.523,93$ ha dengan persentase sebesar $97,55 \%$. Untuk penggunaan tanah yang belum sesuai dengan RTRW adalah seluas 174,28 ha dengan persentase $2,25 \%$. Kemudian untuk penggunaan tanah yang tidak sesuai dengan RTRW seluas 15,45 ha dengan persentase $0,2 \%$. Sebaran ketidaksesuaian dan kesesuaian penggunaan tanah pada tahun 2017 disajikan pada Gambar 4.

Sementara untuk mengetahui tingkat kesesuaian maupun ketidaksesuaian penggunaan lahan di tahun 2021 dilakukan melalui overlay peta penggunaan tanah tahun 2021 dengan RTRW sebagaimana Gambar 5. Pada peta kesesuaian penggunaan tanah tahun 2021 dianalisis bahwa penggunaan tanah yang sesuai dengan RTRW adalah 7.532,71 ha dengan persentase $97,65 \%$. Penggunaan tanah yang belum sesuai seluas 62,65 ha dengan persentase $0,81 \%$. Kemudian untuk penggunaan tanah yang tidak sesuai seluas 118,29 ha dengan persentase $1,53 \%$.

Untuk mengetahui meningkatnya ketidaksesuaian penggunaan tanah pasca dibangunnya jalan Balige bypass maka dilakukan analisis perubahan kesesuaian/ ketidaksesuaian yang terjadi di tahun 2017 dan di tahun 2021 seperti pada Gambar 6. Berdasarkan hasil analisis peta pada Gambar 6 diperoleh bahwa dengan adanya pembangunan jalan Balige bypass mengakibatkan meningkatnya ketidaksesuaian lahan seluas 47,20 Ha, serta perubahan kesesuaian dari belum sesuai menjadi sesuai dengan luas 57,50 ha.

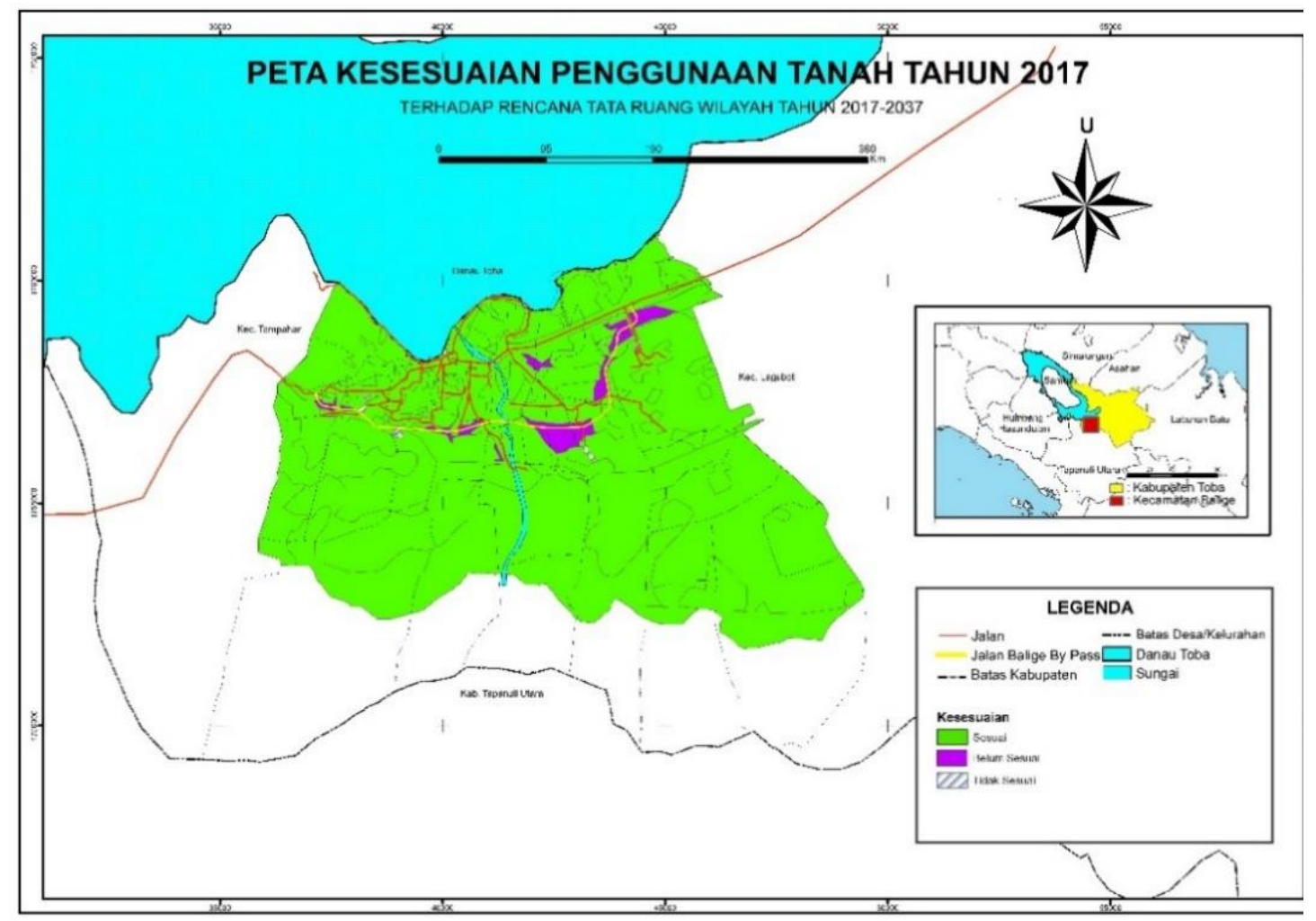

Gambar 4. Peta Kesesuaian Penggunaan Tanah Tahun 2017 
Jurnal Pendidikan Geografi:

Kajian, Teori, dan Praktek dalam Bidang Pendidikan dan Ilmu Geografi $27(1), 2022,1-14$

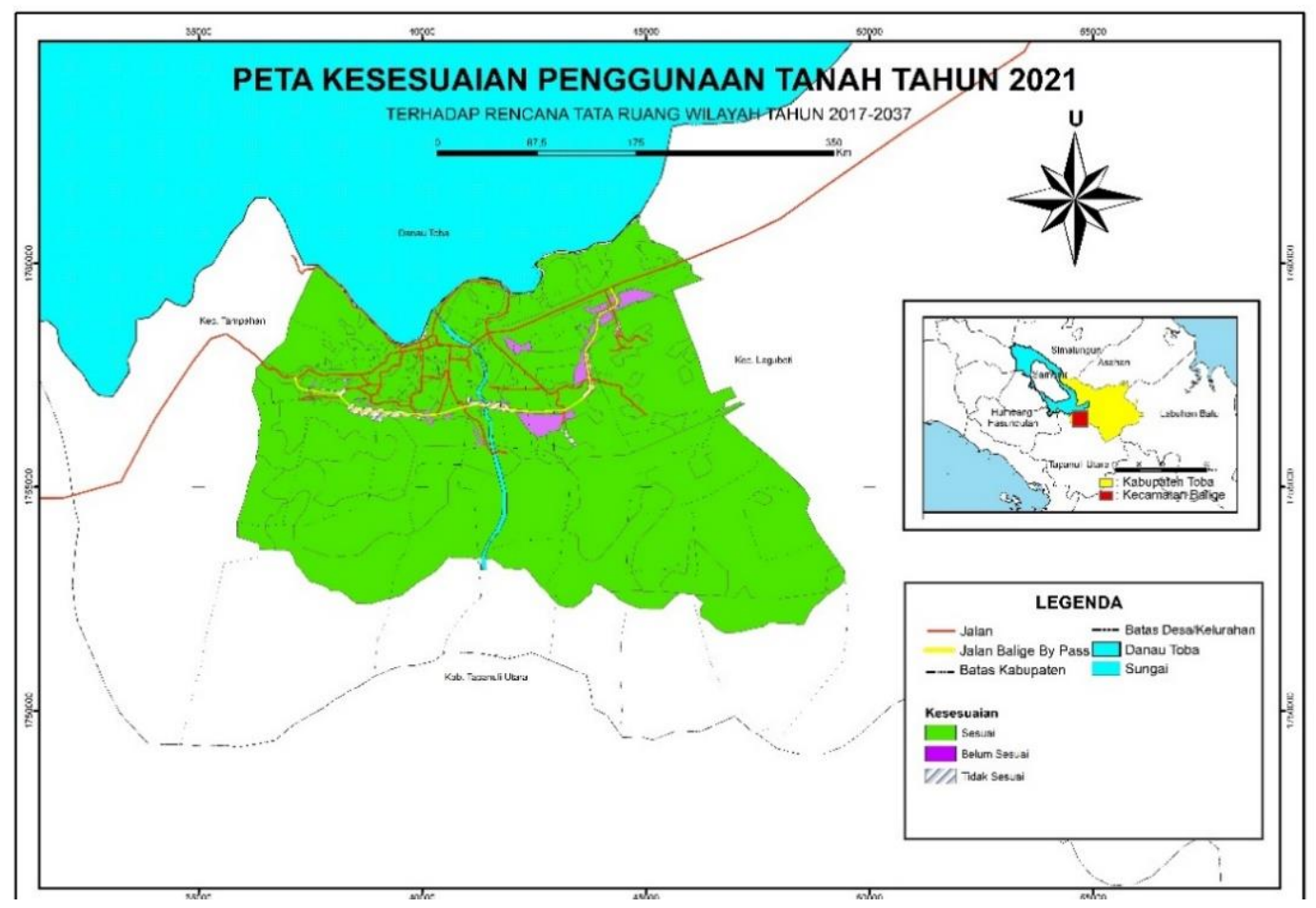

Gambar 5. Peta Kesesuaian Penggunaan Tanah Tahun 2021

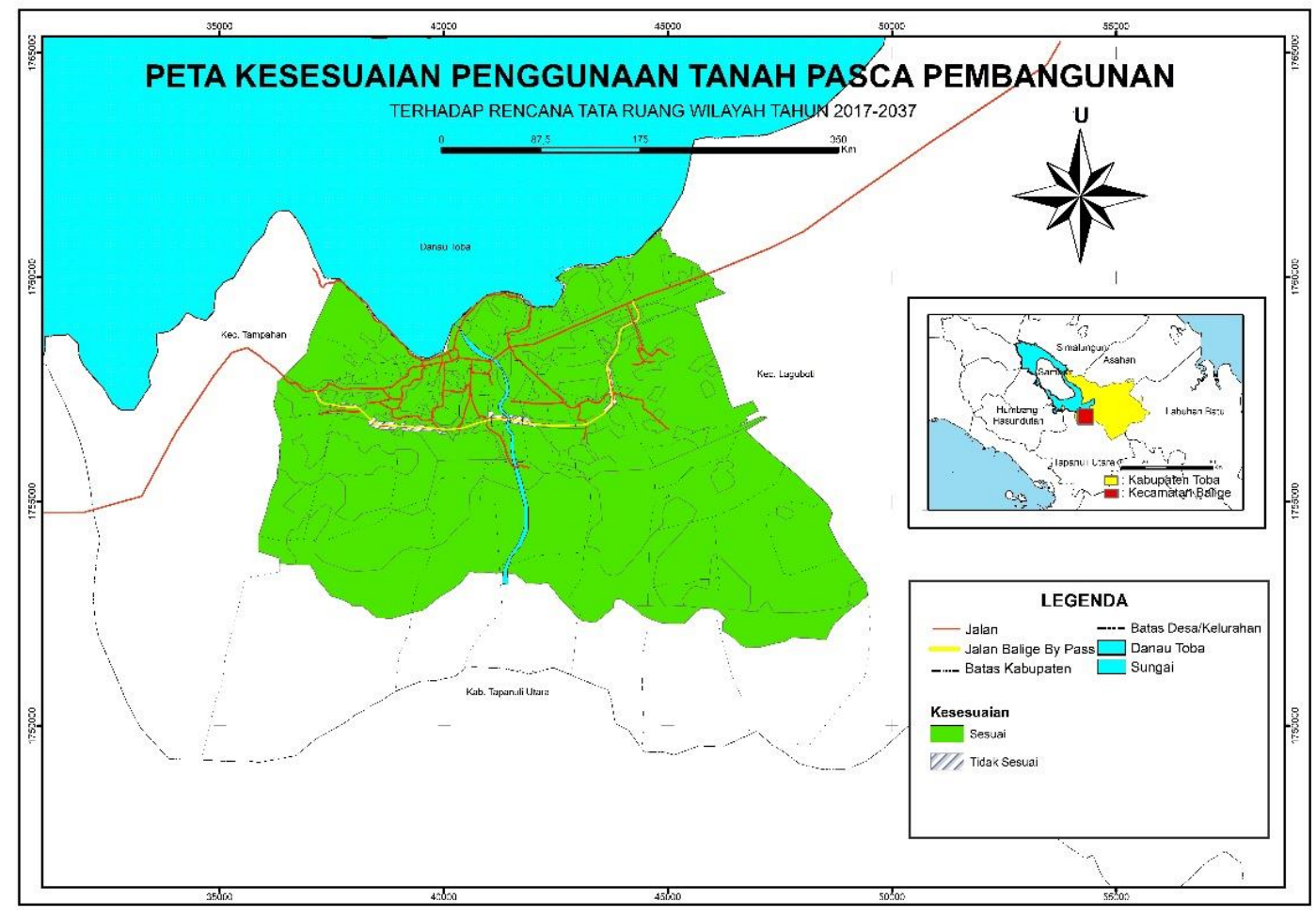

Gambar 6. Peta Kesesuaian Penggunaan Tanah Pasca Pembangunan 
Jurnal Pendidikan Geografi:

Kajian, Teori, dan Praktek dalam Bidang Pendidikan dan Ilmu Geografi

$27(1), 2022,1-14$

\subsection{Kebijakan Penataan Ruang Pasca Pembangunan Jalan Balige Bypass di Kecamatan Balige}

Kebijakan tata ruang memiliki peran penting terhadap pengaturan dan pemanfaatan ruang agar tercipta keberlanjutan dan keseimbangan pemanfaatan fungsi ruang. Untuk mengetahui kebijakan yang dilakukan pasca pembangunan diperlukan data Izin Perubahan Penggunaan Tanah (IPPT) yang terdapat pada Kantor Pertanahan Kabupaten Toba. Berdasarkan analisis data dan wawancara dengan Peresli Silitonga, IPPT sebagai kontrol terhadap alih fungsi lahan kurang berjalan secara maksimal. Hal ini dikarenakan kurangnya pemahaman instansi terkait tentang peraturan penggunaan dan pemanfaatan tanah. Selain itu belum adanya tindakan tegas terhadap adanya semua pelanggaran tata ruang juga berimplikasi terhadap sikap kurang pedulinya masyarakat akan regulasi tata ruang yang telah ditetapkan. Upaya sosialisasi terhadap regulasi RTRW pernah dilakukan oleh Dinas PUPR Kabupaten Toba begitupun beberapa pelanggaran pernah dilakukan teguran (Sekretaris Dinas PUPR Kabupaten Toba). Akan tetapi terbatasnya SDM, mekanisme serta pendanaan terhadap kontrol pemanfaatan ruang mengakibatkan masih banyaknya pelanggaran tata ruang.

Sebagai upaya merumuskan tata ruang yang lebih implementatif dan menyesuaikan kebutuhan akan ruang untuk Kawasan budidaya khususnya kebutuhan pemukiman maka pemerintah Kabupaten Toba berencana melakukan kaji ulang terhadap RTRW yang telah ditetapkan. Selain itu agar regulasi mampu memberikan pengaturan yang lebih rinci maka Pemerintah Kabupaten Toba saat kajian dilakukan sedang melakukan proses penyusunan Rencana Detail Tata Ruang (RDTR) yang akan ditetapkan di tahun 2022 (Sekretaris PUPR Kabupaten Toba).

\section{Simpulan}

Pembangunan infrastruktur jalan Balige bypass berimplikasi pada meningkatnya alih fungsi lahan pertanian (irigasi teknis maupun non teknis) seluas 103, 27 Ha. Kondisi ini tentu berdampak buruk terhadap menurunnya produktivitas pertanian, ketidakberlanjutan kehidupan petani, ketidakseimbangan lingkungan serta mengancam ketahanan pangan. Pemanfaatan citra sentinel dengan resolusi spasial $10 \mathrm{~m}$ mampu menghasilkan peta penggunaan tanah secara up to date sehingga dapat menjadi basis data dalam melakukan monitoring perubahan penggunaan lahan serta monitoring tingkat kesesuaian penggunaan lahan dengan rencana tata ruang. Basis data spasial ini harapannya menjadi dasar dalam melakukan pengendalian dan penertiban pemanfaatan ruang agar tingkat penyimpangan tata ruang dapat ditekan. Penyusunan RDTR juga perlu segera didorong agar pengaturan pemanfaatan ruang mampu disusun secara lebih detail dan lebih implementatif. Upaya monitoring penggunaan lahan ini berperan penting dalam mewujudkan pemanfaatan ruang serta kehidupan masyarakat dan lingkungan yang berkelanjutan. Kajian terkait optimalisasi pemanfaatan penginderaan jauh serta monitoring penggunaan lahan harapannya mampu meningkatkan bahan pembelajaran keilmuan Geografi.

\section{Daftar Rujukan}

Buchori, I., Pangi, P., Pramitasari, A., Basuki, Y., \& Sejati, A. W. (2020). Urban expansion and welfare change in a medium-sized suburban city: Surakarta, Indonesia. Environment and Urbanization ASIA, 11(1), 78101. https://doi.org/10.1177/0975425320909922

Chulafak, G. A., Kushardono, D., \& Zylshal, N. F. N. (2018). Optimasi parameter dalam klasifikasi spasial penutup penggunaan lahan menggunakan data Sentinel SAR. Jurnal Penginderaan Jauh dan Pengolahan Data Citra Digital, 14(2). https://doi.org/10.30536/J.PJPDCD.1017.V14.A2746 


\section{Jurnal Pendidikan Geografi:}

\section{Kajian, Teori, dan Praktek dalam Bidang Pendidikan dan Ilmu Geografi}

$$
\text { 27(1), 2022, 1-14 }
$$

Effendi, P. M. L., \& Asmara, A. (2014). Dampak pembangunan infrastruktur jalan dan variabel ekonomi lain terhadap luas lahan sawah di koridor ekonomi Jawa. Jurnal Agribisnis Indonesia, 2(1), 21-32. https://doi.org/10.29244/jai.2014.2.1.21-32

Festus, I. A., Omoboye, I. F., \& Andrew, O. B. (2020). Urban sprawl: Environmental consequence of rapid urban expansion. Malaysian Journal of Social Sciences and Humanities (MJSSH), 5(6), 110-118. https://doi.org/10.47405/mjssh.v5i6.411

Ghatak, M., \& Mookherjee, D. (2014). Land acquisition for industrialization and compensation of displaced farmers. Journal of Development Economics, 110, 303-312.

Janti, G. I., Martono, E., \& Subejo, S. (2016). Perlindungan lahan pertanian pangan berkelanjutan guna memperkokoh ketahanan pangan wilayah (studi di Kabupaten Bantul, Daerah Istimewa Yogyakarta). Jurnal Ketahanan Nasional, 22(1), 1-22. https://doi.org/10.22146/jkn.16666

Jazuli, A. (2017). Penegakan hukum penataan ruang dalam rangka mewujudkan pembangunan berkelanjutan. Jurnal Rechts Vinding: Media Pembinaan Hukum Nasional, 6(2), 263-282. https://doi.org/10.33331/rechtsvinding.v6i2.156

Kaputra, I. (2015). Alih fungsi lahan, pembangunan pertanian dan kedaulatan pangan. Jurnal Strukturisasi, 1(1), 25-39.

Karmakar, P. (2017). Politics of development: Land acquisition and economic development in India. Journal of Land and Rural Studies, 5(2), 164-182. https://doi.org/10.1177/2321024917703848

Katiandagho, M. Y., Ngangi, C. R., \& Kaunang, R. (2017). Analisi konflik pemanfaatan ruang pada jalur transportasi di kawasan Kota Manado. Jurnal Berkala Ilmiah Efisiensi, 17(02), 72-83.

Khaerani, R., Sitorus, S. R. P., \& Rusdiana, O. (2018). Analysis of land use deviation based on spatial plan in Sumedang Regency. Tata Loka, 20(4), 399-409.

Kusiluka, M. M., Kongela, S., Kusiluka, M. A., Karimuribo, E. D., \& Kusiluka, L. J. (2011). The negative impact of land acquisition on indigenous communities' livelihood and environment in Tanzania. Habitat International, 35(1), 66-73.

Kustiningsih, W. (2017). Kelompok rentan dalam pembangunan kawasan Kota Bandara di Kulon Progo: Studi kasus New Yogyakarta International Aiport (NYIA). Jurnal Pemikiran Sosiologi, 4(1), 91-105. https://doi.org/10.22146/jps.v4i1.23632

Latifah, S. (2014). Perkembangan kota pinggiran (dampak alih fungsi lahan pertanian menjadi perumahan elit). Paradigma, 2(3). https://ejournal.unesa.ac.id/index.php/paradigma/article/view/9077

Muhajir, A. (2017). Kebijakan pengendalian pemanfaatan ruang dalam pelaksanaan ketentuan penataan ruang di Kota Baubau Provinsi Sulawesi Tenggara. Jurnal Renaissance, 2(2), 184-193.

Muryono, S., \& Utami, W. (2020). Pemetaan potensi lahan pertanian pangan berkelanjutan guna mendukung ketahanan pangan. BHUMI: Jurnal Agraria Dan Pertanahan, 6(2), 201-218.

Nixon, D. V., \& Newman, L. (2016). The efficacy and politics of farmland preservation through land use regulation: Changes in Southwest British Columbia's Agricultural Land Reserve. Land Use Policy, 59, 227-240. https://doi.org/10.1016/j.landusepol.2016.07.004

Putri, N. A. (2020). Dinamika perencanaan tata guna lahan di Kabupaten Kediri. Jurnal Ilmiah Administrasi Publik, 6(3), 431-438. https://doi.org/10.21776/UB.JIAP.2020.006.03.12

Rudel, T. K., \& Meyfroidt, P. (2014). Organizing anarchy: The food security-biodiversity-climate crisis and the genesis of rural land use planning in the developing world. Land Use Policy, 36, 239-247. https://doi.org/10.1016/j.landusepol.2013.07.008

Sopanudin, A. (2016). Konflik lahan pertanian dalam pembangunan bandara internasional di Kulon Progo. https://www.academia.edu/30062920/Konflik_Lahan_Pertanian_dalam_Pemabangunan_Bandara_Int ernasional_di_Kulon_Progo_pdf

Sugiono, S. (2007). Metode penelitian kuantitatif, kualitatif dan R \& D. Alfabeta. https://opac.perpusnas.go.id/DetailOpac.aspx?id=133467

Tantja, N. A. D., Utami, W., \& Mujiyati, M. (2021). Dampak pengadaan tanah terhadap perubahan penggunaan lahan dan kondisi sosial masyarakat. GEOGRAPHY: Jurnal Kajian, Penelitian dan Pengembangan Pendidikan, 9(2), 170-182. 
Jurnal Pendidikan Geografi:

Kajian, Teori, dan Praktek dalam Bidang Pendidikan dan Ilmu Geografi

$27(1), 2022,1-14$

Tinambunan, E. V., Findi, M., \& Purnamadewi, Y. L. (2020). Dampak pembangunan infrastruktur dalam mendorong pertumbuhan untuk mengurangi tingkat kemiskinan di Indonesia tahun $2013-2017$. Jurnal Ekonomi dan Kebijakan Pembangunan, 8(1), 20-42. https://doi.org/10.29244/jekp.v8i1.29447

Utami, W., Nurcahyanto, D., \& Sudibyanung, S. (2021). Economic impacts of land acquisition for Yogyakarta International Airport project. MIMBAR: Jurnal Sosial dan Pembangunan, 37(1), 150-160. https://doi.org/10.29313/mimbar.v37i1.6955

Utami, W., Wibowo, Y. A., Hadi, A. H., \& Permadi, F. B. (2021). The impact of mangrove damage on tidal flooding in the subdistrict of Tugu, Semarang, Central Java. Journal of Degraded and Mining Lands Management, 9(1), 3093-3105. https://doi.org/10.15243/jdmlm.2021.091.3093

Verma, P., \& Raghubanshi, A. S. (2019). Rural development and land use land cover change in a rapidly developing agrarian South Asian landscape. Remote Sensing Applications: Society and Environment, 14, 138-147. https://doi.org/10.1016/J.RSASE.2019.03.002

Yin, S., Yang, X., \& Chen, J. (2020). Adaptive behavior of farmers' livelihoods in the context of humanenvironment system changes. Habitat International, 100, 102185. https://doi.org/10.1016/j.habitatint.2020.102185

Yunus, H. S. (2008). Metodologi penelitian wilayah kontemporer. Pustaka Pelajar. http://library.fis.uny.ac.id/opac/index.php?p=show_detail\&id=3158

Zhang, J., Chen, Y., Chen, X., Zhu, C., Huang, B., \& Gan, M. (2021). Identification of potential land-use conflicts between agricultural and ecological space in an ecologically fragile area of Southeastern China. Land, 10(10), 1011. https://doi.org/10.3390/land10101011

Zhou, J., \& Liu, D. (2021). Development proposals of human research protection program. Nursing Ethics, 28(4), 554-562. https://doi.org/10.1177/0969733020952114 